\title{
Effectiveness of an Interprofessional Education Event for Graduate Health Professional Students
}

\author{
Lisa J. Knecht-Sabres \\ Midwestern University - Downers Grove, Iknech@midwestern.edu \\ James F. Gunn \\ Midwestern University, jgunn@midwestern.edu \\ Christine Conroy \\ Midwestern University, cconro@midwestern.edu \\ Sarah E. Getch \\ Midwestern University, sgetch@midwestern.edu \\ Susan M. Cahill \\ Midwestern University, cahillsu@lewisu.edu \\ See next page for additional authors \\ Follow this and additional works at: https://nsuworks.nova.edu/ijahsp \\ Part of the Medicine and Health Sciences Commons
}

This Manuscript has supplementary content. View the full record on NSUWorks here: https://nsuworks.nova.edu/ijahsp/vol14/iss4/2

\section{Recommended Citation}

Knecht-Sabres LJ, Gunn JF, Conroy C, Getch SE, Cahill SM, Lee MM, Ciancio MJ, Jaskolski J, Palmisano L, Kristjansdottir K. Effectiveness of an Interprofessional Education Event for Graduate Health Professional Students. The Internet Journal of Allied Health Sciences and Practice. 2016 Jan 01;14(4), Article 2.

This Manuscript is brought to you for free and open access by the College of Health Care Sciences at NSUWorks. It has been accepted for inclusion in Internet Journal of Allied Health Sciences and Practice by an authorized editor of NSUWorks. For more information, please contact nsuworks@nova.edu. 


\title{
Effectiveness of an Interprofessional Education Event for Graduate Health Professional Students
}

\begin{abstract}
ABSTRACT

Purpose: The purpose of this study was to investigate the impact of a single, optional, half-day, interprofessional education (IPE) event for a myriad of graduate-level health professional students $(n=44)$ at a university in Illinois, USA. Methods: The researchers in this study examined students' performance on two out of six of the domains on the Interprofessiomnal Collaborator Assessment Rubric (ICAR): Roles and Responsibilities and Communication Strategies. This study also investigated quantitative and qualitative findings related to student perceptions regarding this IPE opportunity. Results: Results indicated that students met or exceeded the minimum competency for the ranking of "developing" for all 6 of the behaviors evaluated. Results also revealed that this half-day extracurricuricular IPE event was viewed favorably by health-professional students and created a venue whereby students belonging to different health professional programs can enter into discussions and learn about each others' respective roles and responsibilities in patient care. Conclusion: The creation and implementation of short term extracurricular IPE events may be a valuable alternative for healthcare programs that are unable to implement IPE activities due to some of the common barriers impacting the development, implementation, or continuation of IPE opportunities.
\end{abstract}

\section{Author Bio(s)}

Lisa Jean Knecht-Sabres, DHS, OTR/L is a Professor in the Occupational Therapy Program at Midwestern University.

James F. Gunn, MMS, PA-C, is an Assistant Professor in the Physician Assistant Program at Midwestern University.

Christine Conroy, PT, DPT, MHS, is an Associate Professor in the Physical Therapy Program at Midwestern University.

Sarah E. Getch, Ph.D., is an Assistant Professor in the Behavioral Medicine Program at Midwestern University.

Susan M. Cahill, Ph.D., OTR/L, FAOTA is an Associate Professor and the Program Director of the Occupational Therapy Program at Lewis University.

Michelle M. Lee, Ph.D., ABPP, is a Professor in the Behavioral Medicine Program at Midwestern University.

Mae J. Ciancio, Ph.D., is an Associate Professor in the Biomedical Sciences Program at Midwestern University.

Jayne Jaskolski, Ph.D., CCC- SLP, is an Assistant Professor in the Speech Language Pathology Program at Aurora University.

Lisa Palmisano, Pharm. D., is an Assistant Professor in the Pharmacology Program at Midwestern University.

Kolbrun Kristjansdottir, Ph.D., is an Assistant Professor in the Biomedical Sciences Program at Midwestern University. 


\section{Authors}

Lisa J. Knecht-Sabres, James F. Gunn, Christine Conroy, Sarah E. Getch, Susan M. Cahill, Michelle M. Lee, Mae J. Ciancio, Jayne Jaskolski, Lisa Palmisano, and Kolbrun Kristjansdottir 


\title{
TIAHSP \\ The Internet Joưnal of Allied Health Sciences and Practice \\ Dedicated to allied health professional practice and education
}

Vol. 14 No. 4 ISSN 1540-580X

\section{Effectiveness of an Interprofessional Education Event for Graduate Health Professional Students}

\author{
Lisa J. Knecht-Sabres, DHS, OTR/L ${ }^{1}$ \\ James F. Gunn, MMS, PA-C ${ }^{1}$ \\ Christine Conroy, PT, DPT, FNAP' \\ Sarah E. Getch, Ph.D ${ }^{1}$ \\ Susan M. Cahill, Ph.D., OTR/L, FAOTA² \\ Michelle M. Lee, Ph.D., ABPP1 \\ Mae J. Ciancio, Ph.D ${ }^{1}$ \\ Jayne Jaskolski, Ph.D., CCC- SLP3 \\ Lisa Palmisano, Pharm. D, BCACP1 \\ Kolbrun Kristjansdottir, Ph.D ${ }^{1}$ \\ 1. Midwestern University \\ 2. Lewis University \\ 3. Aurora University \\ United States
}

\begin{abstract}
Purpose: The purpose of this study was to investigate the impact of a single, optional, half-day, interprofessional education (IPE) event for a myriad of graduate-level health professional students $(n=44)$ at Midwestern University in Downers Grove, Illinois. Methods: The researchers in this study examined students' performance on two out of six of the domains on the Interprofessional Collaborator Assessment Rubric (ICAR): Roles and Responsibilities and Communication Strategies. This study also investigated quantitative and qualitative findings related to student perceptions regarding this IPE opportunity. Results: Results indicated that students met or exceeded the minimum competency for the ranking of "developing" for all 6 of the behaviors evaluated. Results also revealed that this half-day extracurricuricular IPE event was viewed favorably by health-professional students and created a venue whereby students belonging to different health professional programs can enter into discussions and learn about each others' respective roles and responsibilities in patient care. Conclusion: The creation and implementation of short term extracurricular IPE events may be a valuable alternative for healthcare programs that are unable to implement IPE activities due to some of the common barriers impacting the development, implementation, or continuation of IPE opportunities.
\end{abstract}

\section{INTRODUCTION}

The purpose of healthcare education is to develop future practitioners who are able to provide high quality services in their respective fields. The Institute of Medicine has proclaimed that all health professionals should be educated to deliver patientcentered care as part of an interdisciplinary team ${ }^{1} \mathrm{~A}$ directive such as this has led to the promotion of interprofessional education (IPE) across many healthcare colleges. The World Health Organization defined IPE as occurring, "when students from two or more professions learn about, from and with each other to enable effective collaboration and improve health outcomes" (p.13). ${ }^{2}$ Many universities and colleges have offered multi-professional courses or courses that are focused on providing knowledge and skills that are relevant to several professions (e.g., anatomy and physiology). However, these courses often lack reflective interaction among students and do not offer opportunities for these future professionals to learn "about, from and with" each other. ${ }^{3}$ 


\section{A Call to Provide Interprofessional Education}

Now, with the focus by professional boards and accrediting bodies on the need to incorporate IPE and/or its underlying tenets into curricula, universities are looking at ways to develop IPE activities on their campuses. ${ }^{4-7}$ Despite this emphasis for more IPE, a recent survey of US medical schools indicated limited implementation of IPE in curricula. ${ }^{8}$ In fact, researchers have asserted that truly collaborative interprofessional practice and education is rare and that most health professional schools operate in a silo fashion with little dialogue, integration, or collaboration between them. ${ }^{3}$

\section{Challenges to Providing Interprofessional Education}

While the concept of introducing IPE to healthcare professional students seems, in theory, to be a relatively easy change, there are significant barriers to the introduction of IPE elements into existing curricula. First and foremost is the lack of evidence that IPE, at the pre-licensing level, has any effect on post-licensing collaboration. ${ }^{9}$ As such, it may be difficult to convince wellestablished education programs to spend time and effort changing curricula to accommodate interprofessional issues when there is little evidence that it makes a lasting impact on professional practice. Besides the potential lack of perceived value, logistical factors, such as time, costs, teaching loads, lack of shared meeting spaces, rigid curricula, incongruent class schedules, differing accreditation standards, and/or turf battles, may make implementation of IPE difficult.10-13 Blue et al concluded that academic calendars, scheduling, and funding were the most significant barriers impacting the development, implementation, or continuation of IPE opportunities in the United States. ${ }^{8}$

Lawlis et al explored the institutional and individual barriers for sustainable IPE. ${ }^{14}$ At the institution level, the most significant barriers to IPE were the lack of financial resources and support, limited faculty development initiatives, varied health professions degree calendars, timetables, and rigid curriculum. However, at the individual level, they found that faculty attitudes, high workload, limited knowledge about other health professions and IPE, lack of perceived value, and issues related to turf as the most prevalent barriers to IPE. Conversely, it is interesting to note that Lawlis et al declared that funding, organizational structures, faculty development, skill of the facilitator, enthusiasm of the faculty, and committed role models were some of the most noteworthy enablers to IPE.14 Given many of the challenges stated above, many educational programs have looked at unique ways to establish IPE on their campuses with minor additional effort on the part of faculty, administration, and resources.

\section{Processes for Providing Interprofessional Education}

Despite an expanse of literature regarding the implementation of IPE into curricula for health professions education, there does not appear to be a consensus on when or how to introduce IPE activities.8,15-18 Oandasen and Reeves suggest that IPE be introduced early in an education program as it can shape an individual's knowledge of one's own profession, as well as help develop more positive attitudes towards other professionals. ${ }^{16}$ In contrast, Parsell and Bligh suggest that students need to have an established professional identity before they can effectively participate in IPE activities. ${ }^{19}$ Regardless of when activities are introduced, most programs appear to utilize a combination of didactic presentations, small group activities, and immersion experiences framed in problem-based or case-based pedagogy with direct involvement in IPE opportunities to build interprofessional leadership skills and competence. ${ }^{10,} 20$ Zhang et al noted that programs with simulation labs often implement IPE activities within these labs to foster teamwork and communication skills. ${ }^{21}$ The literature also provides examples of using service learning to facilitate students' development of interprofessional skills while targeting clinics with underserved individuals and populations. ${ }^{16,18}$ Most of the activities designed to address IPE have been developed to fit into the context of the general preparatory curricula; however, few have focused on extracurricular efforts to promote IPE.

\section{Considering Extracurricular Interprofessional Opportunities}

When considering an extracurricular approach to IPE, it is important to develop activities that are brief enough to accommodate students' dense curricular schedules, but long enough to make the IPE experience meaningful for students. Unfortunately, a search of the literature yielded few examples of one-day IPE initiatives. A study by Schreiber et al reported that a 1-day IPE seminar did not impact attitudes towards IPE for Occupational Therapy (OT) students who participated.22 However, these researchers questioned if the tool utilized to measure the changes was adequate, as there seemed be a ceiling effect with many students entering the activity. Very high pre-activity scores may have made it unlikely that a significant change in score could be detected. ${ }^{22}$ Moreover, these authors asserted that even though there was little detectable change in attitudes, the students appeared to value IPE and the seminar. Regardless of some inconsistencies in the literature, researchers have asserted that it is vital to design and implement time efficient, high-impact learning experiences that engage students in meaningful learning activities that are truly collaborative, interprofessional, and have the capacity to enhance students' understanding of their own role as well as the role of other healthcare providers. ${ }^{23}$ Therefore, the purpose of this study was to 1) investigate the impact of an elective half-day IPE event at a university for a myriad of health professional students at various levels in their didactic education and 2) investigate student perceptions related to the IPE activity.

(C) The Internet Journal of Allied Health Sciences and Practice, 2016 


\section{DESCRIPTION OF PROCESS}

This IPE activity was coordinated and hosted by the College of Health Sciences (CHS) IPE Committee from a mid-size university in Illinois, USA. Members of the IPE committee were faculty from 6 different health-related professions. The different professions represented on the committee included occupational therapy, physical therapy, physician assistant, biomedical sciences, behavioral medicine, and speech language pathology. To help facilitate this activity, faculty members from other health programs at the University were recruited for the event, including faculty members from pharmacy, dentistry, and osteopathic medicine. A maximum of 50 students from nine different health profession programs on campus were invited to sign-up for the activity via an e-mail invitation; attendance was limited to 50 students due to space and resources.

The half-day workshop activity was designed as a case-based exercise. Students were presented a mock patient scenario and then asked to discuss follow-up questions in their assigned interprofessional groups. Before the patient case scenario was presented, the students were briefly introduced to the principles of IPE and interprofessional collaborative practice. The committee developed case materials and questions that were pertinent to each profession in order to assure that the students from all programs would be able to contribute to the discussion regarding the patient's clinical scenario. The following specific objectives for the activity were selected based on the core competencies for interprofessional collaborative practice that were reported by an interprofessional collaborative expert panel: 24

- Students will use the knowledge of one's own role and those of other professions to appropriately discuss and address the healthcare needs of the patients and populations served.

- Students will communicate with other healthcare professionals in an appropriate manner that supports a team approach to patient care.

In total, 44 students from the following health professions attended the event: biomedical sciences $(n=3)$, clinical psychology $(n=8)$, occupational therapy $(n=7)$, osteopathic medicine $(n=3)$, pharmacy $(n=7)$, physician assistant $(n=5)$, speech language pathology $(n=7)$, and dental medicine $(n=4)$. Students were separated into six groups comprised of 6-8 students with each group consisting of at least six different health professions. To ensure the activity would facilitate interprofessional interactions, the final roster for the event was intentionally constructed so that multiple professions were represented at each discussion table. The activity lasted three hours. The case developed for the IPE activity was based on a mock patient with head and neck cancer. To facilitate interprofessional discussions and achievement of the learning objectives, students were expected to discuss questions that were developed by the CHS IPE Committee within their respective groups during three separate break-out sessions. A sample of the questions that were used during the activity to facilitate IPE discussions is provided in Appendix A.

Each group was also assigned a faculty facilitator to help encourage and guide the discussion when needed (total facilitators $=6$ ). All facilitators were informed regarding the types of responses they should expect from the students from different professional programs. In other words, possible questions and answers used to facilitate IPE discussions were identified and discussed by the facilitators prior to the event. All facilitators were also trained on the evaluation measures used for this IPE event.

\section{EVALUATION MEASURES}

\section{Student Satisfaction Survey}

This first measure was a survey designed to capture the students' perspectives about the IPE event. Students were asked to endorse statements regarding their overall satisfaction with the event, their learning as a result of the event, and whether they would recommend the IPE event to another student. The survey responses were based on a 5-point Likert scale with higher scores reflecting greater agreement ( 5 = strongly agree, 4 = agree, 3 = undecided, $2=$ disagree, $1=$ strongly disagree). In addition, the survey included an open ended question where students were able to provide their perspectives about the event. The students' comments were analyzed using a basic interpretive qualitative design.

\section{Interprofessional Collaborator Assessment Rubric}

The second measure consisted of an adapted version of the Interprofessional Collaborator Assessment Rubric (ICAR), a criterionbased rating scale that was used by the faculty facilitators to rate the students' performance on two dimensions, roles and responsibilities and communication strategies. ${ }^{15,25}$ The ICAR was developed to assess learners' achievement as well as to provide constructive feedback for those looking to further develop their competency in interprofessional settings. ${ }^{15}$ It has been validated through several methods including a typological analysis of national and international competency frameworks, a Delphi survey of experts, and interprofessional focus groups with students and faculty. ${ }^{15}$ In order to better focus on the current IPE event's specific objectives, the ICAR was modified to include only six items from the two domains that address Roles and Responsibilities and

(c) The Internet Journal of Allied Health Sciences and Practice, 2016 
Communication Strategies. The first three items used in this study focused on the roles and responsibilities of the student and assessed the students' ability to: a) describe their own role as a healthcare professional with the team/patient/family, b) identify and discuss with the team their own limitations as a healthcare professional, and c) identify and share evidence-based practice with the team. The next three items focused on communication strategies and assessed the students' ability to: a) communicate with the team in a logical way, b) explain discipline specific jargon, and c) listen actively and encourage ideas from other healthcare professionals in training. Students' competence level was assessed by trained faculty facilitators and rated on a Likert-type scale with scores ranging from one to four ( $1=$ minimal; $2=$ developing; $3=$ competent; $4=$ mastery $)$ with higher scores reflecting a higher level of competence. Many scores were assigned throughout the event, however, facilitators did not finalize scores until the end of the event when student participation ceased.

\section{RESULTS}

There were a total of 42 student satisfaction surveys completed from the group of 44 various healthcare professional students present. Results from the student satisfaction survey indicated that students, in general, felt the IPE event was a very positive experience. Specifically, students agreed to strongly agreed, on average, that they were satisfied overall with the IPE event. Additionally, students agreed to strongly agreed, on average, that they learned new information and that they would recommend the IPE event to fellow students (Table 1).

Qualitative comments on the survey supported the students' favorable rating of the event, indicating that the students 1) were satisfied with the event, 2) learned something new, and 3) would recommend this event to a fellow student. The following quotes represent the type of qualitative feedback received.

"This event was such a great experience! This is so important for every student to experience this type of interaction with other health professionals. This is an amazing way to learn about each other and the different professions and how we can collaborate. I would HIGHLY advocate this type of program to be installed into each curriculum."

"Really enjoyed learning to work with other professions and looking at the patient from all aspects. I learned a lot about what other professions can do to help the patient and how I can work with them to help better the patient. Really glad I came. Great experience."

"The event was extremely well-organized and executed. It was tremendously beneficial to my educational experience. I would highly recommend this to all students. "

The facilitators $(n=6)$ of each group evaluated between 6-8 students from varied healthcare professions (total evaluations, $N=$ 44). Overall, the results from the modified ICAR indicated that students demonstrated a level of competency as categorized as "developing to competent" in their ability to a) describe their own role as a healthcare professional with the team, b) identify and share evidence-based practice with the team, and c) explain discipline specific jargon to the team. Students' ability to identify and discuss with the team their own limitations as a healthcare professional was assessed, on average, as being "competent". Further, results indicated that, on average, students' level of competency was that of "competent to mastery" with regard to their ability to a) communicate with the team in a logical way and b) listen actively and encourage ideas from other healthcare professionals in training. Overall, students met or exceeded the minimum competency for the ranking of "developing" for all of the behaviors evaluated (Table 2).

\section{DISCUSSION}

In conclusion, the results regarding this IPE event were very positive. Both quantitative data and qualitative comments indicated that students found the half-day IPE event to be satisfying, a source of new learning, and worthy of recommendation to other students. Moreover, students demonstrated behaviors that met or exceeded the minimum competency expectatations related to their own professional role and in communication.

Researchers suggest that IPE is most effective when a) principles of adult learning are used, b) learning methods reflect real world practice, and c) interactions occur between students. ${ }^{26}$ Perhaps, part of the reason for the successful outcome of this IPE event was related to the fact that the investigators in this study intentionally designed an IPE event which addressed all three of these concepts. It is also possible that since the students in this study volunteered to take part in an IPE event on a weekend morning, they already possessed a positive attitude towards IPE and were potentially more open-minded and receptive to developing IPE skills and more motivated to interact with other students in varied professional schools.

Faculty members, providing representation of multiple health professions, were involved throughout the creation of the IPE activity and reached consensus regarding the presentation of the case, discussion questions, and student assessments. The researchers of this study concluded that it was vital that representatives from all professional disciplines be involved in the developmental

(C) The Internet Journal of Allied Health Sciences and Practice, 2016 
phases of IPE events. They found this process helped deepen their own understandings of colleagues' professional roles and responsibities, which is key to interprofessional practice.

The researchers in this study concluded that it would be beneficial to include more specific anchors on the rubric of the evaluation tool. As the rubric stands now, anchors included broad assessments of skills and included descriptors such as does not, occasionally, frequently, and consistently describe one's professional roles and responsibilities, explain discipline-specific jargon, or share evidence-based or best practice discipline-specific knowledge with others. The researchers in this study felt that the inclusion of specific behavioral anchors (e.g., identifies at least one method of best-practice specific to profession, demonstrates active listening by reflecting back information) both in the rubric and in the facilitor training could be beneficial and might further strengthen inter-rater reliability.

\section{IMPLICATIONS}

The literature suggests that there are significant barriers that may prevent healthcare institutions from offering IPE experiences within curricula. ${ }^{8}$ However, the results from this study suggest that the implementation of a brief IPE activity, outside of the students' general professional curricula, might be a solution to enhance IPE in healthcare colleges and universities. It may also serve as an effective primer for encouraging interest in IPE among faculty members. This study provides preliminary evidence for the impact of brief IPE interventions. There appears to be a vital need to create, implement, and assess the effectiveness of high-impact learning experiences that engage students in meaningful learning activities which are truly collaborative and interprofessional. ${ }^{27}$ Preliminary evidence suggests that quality IPE experiences have the capacity to enhance students' understanding of their own role and the role of other healthcare providers, improve professional interactions, and enhance the quality of care for patients and clients. ${ }^{27}$

\section{LIMITATIONS}

This study was conducted with a relatively small sample and at one, graduate-level, healthcare university in Illinois, USA. Therefore, the outcomes of this study may not be directly generalizeable to all healthcare college and universities. Also, this study only examined two IPE domains: interprofessional communication and roles and responsibilities. Future studies should include the investigation of other IPE behaviors. Further, many of the investigators involved in this study were also members of the IPE committee that designed and implemented the IPE event. Finally, the students that participated in this IPE activity were at different points in their respective curricula; thus, they may not have had the exposure to all of the necessary pre-requisite information in their program to thoroughly address all of the clinical components associated with the case. This may have limited some students' participation, which in turn may have resulted in a lower compentency scores provided by the facilitator.

\section{FUTURE DIRECTIONS}

Future studies should investigate if brief IPE activities can produce similar results with larger student populations and if such activities influence IPE behaviors in other domains. Future studies could also focus on evaluating inter-rater reliabilty on the faculty ICAR ratings. In addition, the best methods for training faculty facilitiators on rating the ICAR should be explored. Finally, future investigations could compare and contrast students' perceptions related to brief IPE activities like the one described in this study with other activities (e.g., journal clubs) to determine the most effective and efficent mechanism for enhancing interprofessonal behvaiors.

\section{CONCLUSION}

Interprofessional collaboration is becoming increasingly valued, even though professionals in educational and healthcare settings trend toward remaing siloed. The implementation of interprofessional educational activities in healthcare universities has the potential to foster interprofessional behaviors in students. The results of this study show that a half-day extracurricuricular IPE event is viewed favorably by health-professional students and creates a venue whereby students belonging to different health professional training programs can enter into discussion and learn about each others' respective roles and responsibilities in patient care. The creation and implementation of short term extracurricular IPE events may be a valuable alternative for healthcare programs that are unable to implement IPE activities due to some of the common barriers of incorporating IPE.

\section{DECLARATION OF INTEREST}

The authors report no declaration of interest. The authors alone are responsible for the writing and content of this article. This study was approved by Midwestern University's Institutional Review Board. 


\section{REFERENCES}

1. Institute of Medicine: Committee on Quality of Healthcare in America. Crossing the quality chasm: A new health system for the 21st century. Washington, DC: National Academy Press. 2001. Retrieved from

http://www.nap.edu/catalog/10027/crossing-the-quality-chasm-a-new-health-system-for-the, Accessed July 27, 2016.

2. World Health Organization Framework for action on interprofessional education and collaborative practice. 2010. http://www.who.int/hrh/resources/framework_action/en/ Accessed July 27, 2016.

3. Earnest M, Brandt B. Aligning practice redesign and interprofessional education to advance triple aim outcomes. J Interprof Care. 2014;28(6):497-500. [PMID: 25029535] DOI: 10.3109/13561820.2014.933650

4. Accreditation Council for Occupational Therapy Education (ACOTE). Accreditation standards for a master's degree level educational program for the occupational therapist. The American Occupational Therapy Association, Inc. 2011. Retrieved from http://www.aota.org. Accessed July 27, 2015.

5. Accreditation Council for Pharmacy Education (ACPE). Accreditation standards and key elements for the professional program in pharmacy leading to the doctor of pharmacy degree. Chicago, IL. 2016. Retrieved from https://www.acpeaccredit.org/pdf/Standards2016FINAL.pdf. Accessed July 27, 2016.

6. Accreditation Review Commission on Education for the Physician Assistant, Inc., (ARC-PA). Accreditation standards for physician assistant education. 2014. Retrieved from: http://www.arc-pa.org/accreditation/. Accessed July 27, 2016.

7. Commission on Accreditation in Physical Therapy Education. Evaluative criteria for accreditation of PT programs. 2014.

Retrieved

from http://www.capteonline.org/uploadedFiles/CAPTEorg/About_CAPTE/Resources/Accreditation_Handbook/EvaluativeCriteria PT.pdf. Accessed July 27, 2016.

8. Blue AV, Zoller J, Stratton TD, Elam CL, Gilbert, J. Interprofessional education in US medical schools. J Interprof Care. 2010;24(2):204-6. [PMID: 20148622] DOI: 10.3109/13561820903442887

9. Zwarenstein M, Reeves S, Perrier L. Effectiveness of pre-licensure interprofessional education and post-licensure collaborative interventions. J Interprof Care. 2005 May 19;19(suppl 1):148-65. [PMID: 16096152] DOI: $10.1080 / 13561820500082800$

10. Abu-Rish E, Kim S, Choe L, Varpio L, Malik E, White AA, et al. Current trends in interprofessional education of health science students: a literature review. J Interprof Care. 2012 nov;26(6):444-51. [PMID: 22924872] Doi: 10.3109/13561820.2012.715604

11. Buring SM, Bhushan A, Broeseker A, Conway S, Duncan-Hewitt W, Hansen L, Westberg S. Interprofessional Education Supplement in Interprofessional Education: Definitions, Student Competencies and Guidelines for Implementation. Am J Pharm Educ. 2009 Jul;73(4):59. [PMID: 19657492]

12. Curran VR, Deacon DR, Fleet L. Academic administrators' attitudes towards interprofessional education in Canadian schools of health professional education. J Interprof Care. 2005 May;19(Suppl 1):76-86. [PMID: 16096147] DOI: 10.1080/13561820500081802

13. Rees D, Johnson R. All together now? Staff views and experiences of a prequalifying interprofessional education curriculum. J Interprof Care. 2007 Oct;21(5):543-55. [PMID: 17891627] DOI: 10.1080/13561820701507878

14. Lawlis TR, Anson J, Greenfield D. Barriers and enablers that influence sustainable interprofessional education: a literature review. J Interprof Care. 2014 jul;28(4):305-10. [PMID: 24625198] http://dx.doi.org/10.3109/13561820.2014.895977.

15. Curran VR, Sharpe D, Flynn K, Button P. A longitudinal study of the effect of an interprofessional education curriculum on student satisfaction and attitudes towards interprofessional teamwork and education. J Interprof Care. 2010 Jan;24(1):41-52. [PMID: 19705318] DOI: 10.3109/13561820903011927

16. Oandasan I, Reeves S. Key elements of interprofessional education. Part 2: Factors, processes, and outcomes. J Interprof Care. 2005 May;19(Suppl 1):39-48. [PMID: 16096144] DOI: 10.1080/13561820500081703

17. Reeves S, Zwarenstein M, Goldman J, Barr H, Freeth D, Koppel I, Hammick M. The effectiveness of interprofessional education: key findings from a new systematic review. J Interprof Care. 2010 May;24(3):230-41. [PMID: 20178425] DOI: $10.3109 / 13561820903163405$

18. Thistlethwaite J. Interprofessional education: A review of context, learning and the research agenda. Med Educ. 2012 Jan;46(1):58-70. [PMID: 22150197] DOI: 10.1111/j.1365-2923.2011.04143.x

19. Parsell J. Bligh. Interprofessional Learning. Postgrad Med J. 1998;74:89-95.

20. Freeth D, Hammick M, Reeves S, Koppel I, Barr H. Effective Interprofessional Education: Development, Delivery and Evaluation. London: Blackwell; 2005

21. Zhang C, Thompson S, Miller C. A review of simulation-based interprofessional education. Clin Sim Nurs. 2011;7:e117-26.

22. Schreiber J, Goreczny A, Bednarek M, Hawkins S, Hertweck M, Sterrett S. The effects of a single event interprofessional education (IPE) experience on occupational therapy students' attitudes toward IPE. Inter J Allied Health Sc Prac. 2014;12(1):1-8. 
23. Grapczynski C, Schuurman S, Booth AD, Bambini D, Beel-Bates C. The integrated model for interprofessional education: A design for preparing health profession's students to work in interprofessional teams. J Allied Health. 2015 Summer;44(2):10814. [PMID: 26046119]

24. Panel IECE Core competencies for interprofessional collaborative practice: Report of an expert panel. Washington, D.C.: Interprofessional Education Collaborative. 2011.

25. Hayward M, Curran VR, Schultz H, Curtis B, Murphy S. Reliability of the Interprofessional Collaborator Assessment Rubric (ICAR) in Multi Source Feedback (MSF) with post-graduate medical residents. BMC Med Educ. 2014 Dec;14:1049. [PMID: 25551678] doi:10.1186/s12909-014-0279-9

26. Knowles M, Holton E, Swanson R. The Adult Learner: The Definitive Classic in Adult Education and Human Resources Development. Houston, TX: Gulf Publishing Company; 1998.

27. Remington T, Foulk MA, Williams BC. Evaluation of evidence for interprofessional education. Am J Pharm Educ. 2006 Jun;70 (3):66(1-7). [PMID: 17136186] http://www.ncbi.nlm.nih.gov/pmc/articles/PMC1636959/pdf/ajpe66.pdf 
